\section{A Descending Pathway with Monosynaptic Action on Flexor Motoneurones}

Alpha motoneurones of the lumbosacral region in the cat receive monosynaptic EPSPs from descending pathways $^{\mathbf{1 , 2}}$. Extensor motoneurones receive this action from the ipsilateral lateral vestibular (Deiters') nucleus ${ }^{2}$. The pathway to flexor motoneurones also descends from supraspinal centres but does not originate in Deiters' nucleus ${ }^{2}$. The aim of the present experiments has been to find the origin of the pathway from which monosynaptic EPSPs can be evoked in flexor motoneurones.

Cats anaesthetized with chloralose and paralysed with Flaxedil were used for intracellular recording from motoneurones. Stereotaxic stimulation was made in the brain stem after vermal cerebellectomy with a thin tungsten electrode (insulated but for the tip) against an indifferent electrode in the neck muscles. At the lower thoracic level, the dorsal columns were removed for about two segments and the spinal cord hemisectioned contralateral to the side of motoneuronal recording. The ventral roots were left intact. Microelectrodes filled with $2 M \mathrm{~K}$-citrate and a resistance of 3-5 M $\Omega$ were used. Recordings were made from 25 flexor motoneurones in which a monosynaptic EPSP was evoked on stimulation of ventrolateral funicles

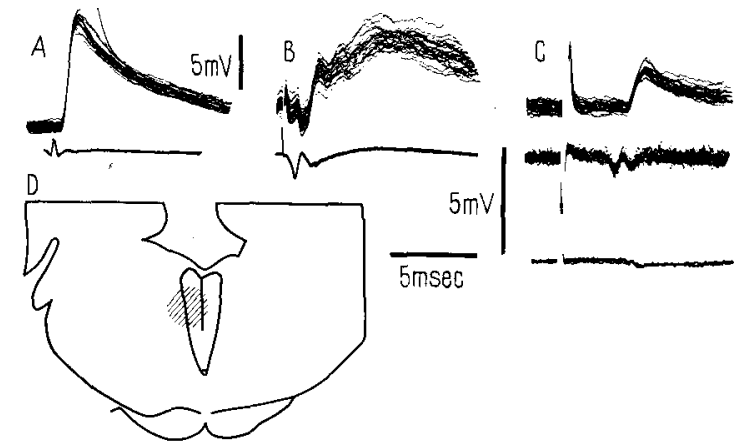

The upper traces in $\mathrm{A}-\mathrm{C}$ are intracellular recordings from a posterior biceps-semitendinosus (PBSt) motoneurone. The lower traces in A and $\mathrm{B}$ and the middle trace in $\mathrm{C}$ are recorded from the $\mathrm{L} 7$ dorsal root entry zone. Lowermost trace in $\mathrm{C}$ is recorded after withdrawal of the microelectrode to a just extracellular position. Voltage calibration refers to microelectrode recordings only. A shows the maximal monosynaptic Ia EPSP from the PBSt nerve. B shows the effect of supramaximal stimulation of the ipsilateral ventrolateral funicles in the lower thoracic region. In $\mathrm{C}$ the brain stem is stimulated in the hatched area in the drawing (D), which represents a transverse section of the brain stem at a level $6.5 \mathrm{~mm}$ rostral to obex. in the thoracic region (Figure, B). The cells were identified by antidromic stimulation of the axon at a peripheral level. A monosynaptic EPSP can be evoked in flexor motoneurones from a dorsomedial region in the upper medulla and lower pons. Figure, $\mathrm{C}$ shows that stimulation of this region produces a descending volley conducted at about $120 \mathrm{msec}$ (middle trace in C) and an EPSP in a flexor motoneurone after a segmental latency of $0.6 \mathrm{msec}$, which shows that the linkage is monosynaptic. The amplitude of the EPSP from the brain stem corresponds to the amplitude of the early EPSP evoked by maximal stimulation of the ipsilateral ventrolateral funicles (Figure, B) and is about $25 \%$ of the amplitude of the maximal homonymous Ia EPSP (Figure, A; note different voltage calibration in A and B). Careful exploration in a transverse plane revealed that the effect is evoked at very low threshold $(<0.05 \mathrm{~mA})$ from the hatched region in the drawing. The region extends for several millimetres in a rostrocaudal direction, but there was a large increase in threshold when the stimulating electrode was moved in the rostral direction to the midpontine level.

Fibres from different centres descend in the region from which these low threshold effects are evoked ${ }^{3}$, and it is not possible to disclose the origin of the axons with monosynaptic effect on flexor motoneurones only from the stimulation experiments. However, there is evidence that the axons do not originate from the medial vestibular nucleus because descending monosynaptic EPSPs can be evoked in flexor motoneurones from the thoracic region several weeks after complete destruction of the ipsilateral medial vestibular nucleus ${ }^{4}$. Our stimulation experiments suggest that the axons do not come from centres rostral to the lower pons. It is tentatively suggested that the pathway with monosynaptic connection to flexor motoneurones is reticulospinal.

Zusammentassung. Erregung eines dorsomedialen Stammhirngebietes verursacht ein monosynaptisches EPSP in Motoneuronen der Beugemuskeln.

\section{S. GRILLNER and S. LUND}

Department of Physiology, University of Göteborg (Sweden), December 20, 1965.

1 E. Eide, A. Lundberg, and P. Voorhoeve, Acta physiol. scand. 53, 185 (1961).

2 S. Lund and O. Pompeiano, Experientia 27, 602 (1965).

3 R. Nyberg-Hansen, J. Comp. Neur. 124, 71 (1965).

4 S. Lund and O. Pompeiano, unpublished.

\section{Action of Cortisone on Human Fibroblasts in vitro}

Human embryonic cells can be maintained for several months in vitro with retention of some of their in vivo properties ${ }^{1,2}$. These cells are probably derived from mesenchymal cells. Therefore, since cortisone is one of the factors controlling the metaoblism of mesenchymal tissue in vivo ${ }^{3}$, it seems important to study the behaviour of these cells when they are exposed to a medium containing this hormone.

1 H. E. Swim and R. T. PARker, Am. J. Hyg. 66, 235 (1957). 2 L. HAYFLICK and P. S. MoorheAd, Expl Cell Res. 25, 585 (1961). ${ }^{3}$ C. W. CASTOR, Endocrinology 47, 234 (1950). 